\title{
Lunar Lander Offloading Operations Using a Heavy-Lift Lunar Surface Manipulator System
}

\author{
Sharon A. Jefferies ${ }^{1}$, William R. Doggett ${ }^{2}$ \\ NASA Langley Research Center, Hampton, VA, 23681 \\ Jonathan Chrone ${ }^{3}$, Scott Angster ${ }^{4}$, \\ Analytical Mechanics Associates, Hampton, VA, 23666 \\ John T. Dorsey ${ }^{5}$, Thomas C. Jones ${ }^{6}$ \\ NASA Langley Research Center, Hampton, VA, 23681 \\ Michael E. Haddad ${ }^{7}$ \\ NASA Kennedy Space Center, FL, 32899 \\ David A. Helton, ${ }^{8}$ and Darrell L. Caldwell Jr. ${ }^{9}$ \\ Analytical Mechanics Associates, Hampton, VA, 23666
}

\begin{abstract}
This study investigates the feasibility of using a heavy-lift variant of the Lunar Surface Manipulator System (LSMS-H) to lift and handle a 12 metric ton payload. Design challenges and requirements particular to handling heavy cargo were examined. Differences between the previously developed first-generation LSMS and the heavy-lift version are highlighted. An in-depth evaluation of the tip-over risk during LSMS-H operations has been conducted using the Synergistic Engineering Environment and potential methods to mitigate that risk are identified. The study investigated three specific offloading scenarios pertinent to current Lunar Campaign studies. The first involved offloading a large element, such as a habitat or logistics module, onto a mobility chassis with a lander-mounted LSMS-H and offloading that payload from the chassis onto the lunar surface with a surface-mounted LSMS-H. The second scenario involved offloading small pressurized rovers with a landermounted LSMS-H. The third scenario involved offloading cargo from a third-party lander, such as the proposed ESA cargo lander, with a chassis-mounted LSMS-H. In all cases, the analyses show that the LSMS-H can perform the required operations safely. However, Chariot-mounted operations require the addition of stabilizing outriggers, and when operating from the Lunar surface, LSMS-H functionality is enhanced by adding a simple ground anchoring system.
\end{abstract}

\section{Nomenclature}

$\alpha=$ slew $1 / 2$ angle

$\beta=$ guy angle relative to the horizontal

$\beta \mathrm{R}=\mathrm{LSMS}$ length from shoulder to elbow

\footnotetext{
${ }^{1}$ Research Aerospace Engineer, Space Mission Analysis Branch, MS-462, Senior Member.

${ }^{2}$ Senior Research Engineer, Structural Concepts and Mechanics Branch, MS-190, Member.

${ }^{3}$ Project Engineer, Space Mission Analysis Branch, 303 Butler Farm Rd, Hampton, VA, 23666, Member.

${ }^{4}$ Senior Engineer, Space Mission Analysis Branch, 303 Butler Farm Rd, Hampton, VA, 23666.

${ }^{5}$ Senior Research Engineer, Structural Concepts and Mechanics Branch, MS-190, Associate Fellow.

${ }^{6}$ Research Engineer, Structural Concepts and Mechanics Branch, MS-190, Member.

${ }^{7}$ Senior Systems Engineer, Systems Engineering and Integration, LX-S1.

${ }^{8}$ Multimedia Specialist, Advanced Concepts Lab, 303 Butler Farm Rd, Hampton, VA, 23666.

${ }^{9}$ Senior Project Engineer, Space Mission Analysis Branch, 303 Butler Farm Rd, Hampton, VA, 23666.
} 


$\begin{array}{ll}\mathrm{CG} & =\text { center of gravity } \\ \mathrm{CMC} & =\text { Crew Mobility Chassis } \\ \mathrm{d}_{\mathrm{i}}, \mathrm{d}_{\mathrm{j}} & =\text { perpendicular distance between tipping fulcrum and CG vector of elements to left and right } \\ \mathrm{dc}_{\text {critical }} & =\text { horizontal distance from the tipping fulcrum to the insipient tip over limit using chassis mount } \\ \mathrm{dd}_{\text {critical }} & =\text { horizontal distance from the tipping fulcrum to the CG of down-slope payloads } \\ \mathrm{du}_{\text {critical }} & =\text { horizontal distance from the tipping fulcrum to the CG of up-slope payloads } \\ \mathrm{F}_{\mathrm{a},} \mathrm{F}_{\mathrm{c}} & =\text { reaction forces on the left or right of the tipping fulcrum } \\ \mathrm{F}_{\text {guy }} & =\text { force in the guy wire } \\ \mathrm{F}_{\text {groundanchor }} & =\text { force in the ground anchor } \\ \mathrm{g}_{1} & =\text { lunar gravity } \\ \mathrm{h}_{\mathrm{cg}} & =\text { CG height } \\ \mathrm{h}_{\mathrm{gm}} & =\text { ground mount height } \\ \mathrm{LSMS} & =\text { Lunar Surface Manipulator System } \\ \mathrm{LSMS}-\mathrm{H} & =\text { Heavy-lift Lunar Surface Manipulator System } \\ \mathrm{LSS} & =\text { Lunar Surface Systems } \\ \mathrm{l}_{\text {chariot }} & =\text { chassis length } \\ \mathrm{lp}_{\text {lsms }} & =\text { distance between LSMS and chassis when chassis-mounted } \\ \mathrm{M}_{(\mathrm{element})} & =\text { element mass } \\ \mathrm{m}_{\mathrm{i}}, \mathrm{m}_{\mathrm{j}} & =\text { mass of elements to left and right of tipping fulcrum } \\ \mathrm{R} & =\text { maximum LSMS reach } \\ \eta & =\text { LSMS shoulder height to reach ratio } \\ \theta_{1} & =\text { LSMS kingpost rotation angle } \\ \theta_{2} & =\text { LSMS shoulder rotation angle } \\ \theta_{3} & =\text { LSMS elbow rotation angle }\end{array}$

\section{Introduction}

S we consider returning humans to the Moon with a view towards building an outpost to enable a permanent Ahuman presence, it is important to consider the means by which lunar surface system elements and other cargo will be offloaded from the lunar lander as well as handled on the surface. In particular, methods to offload heavy cargos, such as surface habitats, from lunar landers and to manipulate that cargo on the surface of the Moon need to be investigated. Previous studies have focused on using a Lunar Surface Manipulator System ${ }^{1}$ to offload cargos up to $\sim 6$ metric tons and the All-Terrain Hex-Legged Extra-Terrestrial Explorer (ATHLETE) for offloading cargos up to the maximum lander capacity. ${ }^{2}$ In this study, we investigated the use of a Lunar Surface Manipulator System (LSMS) that has been modified to handle a 12 metric ton payload, which is consistent with the estimated mass of the largest payloads currently used in NASA's Lunar Campaign Analysis.

This study focused on two key areas: a) identifying necessary design modifications to enable the LSMS to handle the heavier cargo mass and to ensure the LSMS could reach all potential cargos from lander, chassis, and surface mounted locations, and b) analyzing payload handling operations with the Heavy-lift LSMS (LSMS-H) to ensure the operations could safely be performed while avoiding a potential tip over situation. As part of the analysis, preliminary calculations were made to identify the safe operation envelope, or tip over boundaries, for several cargo handling scenarios. These initial calculations helped to identify necessary design modifications to expand the safeoperating zone and reduce the likelihood of tip over. The results were then fed into the Synergistic Engineering Environment (SEE) ${ }^{3}$. The SEE was used to simulate each offloading scenario, dynamically calculating the system center of gravity (CG) (assuming a constant gravity field) and comparing the CG location to the tip over boundary.

In addition to the operational focus areas described above, this study also sought to understand the correlation between lunar cargo handling equipment and procedures using their terrestrial equivalents, particularly those that may facilitate remote offloading operations without the presence of crew on the lunar surface. As several of the payload handling operations will potentially occur in preparation for crewed missions, it is essential that payload acquisition and release be as simple and safe as possible to reduce risk to lunar equipment. Several benefits are identified that may be realized by incorporating commonality into the development of lunar and terrestrial flight handling hardware and procedures. 


\section{Background}

\section{A. The LSMS}

Devices for lifting, translating and precisely placing payloads are critical for efficient Earth-based construction operations. Recent and past studies have demonstrated that devices with similar functionality will be needed to support lunar outpost operations. ${ }^{4,5}$ Lunar payloads include: a) prepackaged hardware and supplies that must be unloaded from landers and then accurately located at their operational site, b) sensor packages used for periodic inspection of landers, habitat surfaces, etc., and c) local materials such as regolith that require excavation and grading. ${ }^{6}$ Although several designs have been developed for Earth based applications, these devices lack unique design characteristics necessary for transport to and use on the harsh lunar surface. ${ }^{7}$ These design characteristics include: a) lightweight components, b) compact packaging for launch, c) automated deployment, d) simple in-field reconfiguration and repair, and e) support for tele-operated or automated operations. Also, because the cost to transport mass to the lunar surface is very high, the number of devices that can be dedicated to surface operations will be limited. Thus, in contrast to Earth-based construction, where many single-purpose devices dominate a construction site, a lunar outpost will require a limited number of versatile devices which provide operational benefits both during the initial construction phase and throughout the lifetime of the outpost.

The LSMS has many unique features resulting in a mass efficient solution to payload handling on the lunar surface. Typically, the LSMS device mass is estimated at approximately $3 \%$ of the mass of the heaviest payload lifted at the tip, or $1.8 \%$ of the mass of the heaviest mass lifted at the elbow (or mid-span of the boom) for a high performance variant incorporating advanced structural components. ${ }^{8}$ A unique feature of the design is spreaders that act like spokes on a wheel to maintain mechanical advantage about the joints as the joint rotates. These spreaders disengage allowing the tension members to lift off for improved joint range of motion providing a large operational workspace. As a result, unique operational configurations, such as a fork-lift mode that allows the LSMS to reach under landers or shelters, are possible. To facilitate repositioning between tasks, the LSMS can grapple a fixture at its wrist joint, release its base, and relocate the base enabling the LSMS to walk off the lander or move from a mobility vehicle to a fixed location. The LSMS also has the ability to automatically acquire various end effectors at the wrist that enable additional support operations such as construction, regolith handling, and equipment inspection.

\section{B. Study parameters}

This study was undertaken in support of NASA's Lunar Surface Systems (LSS) Project and, as such, focused on offloading operations using the LSS element concepts being considered at the time the study took place. These elements included the Altair Lander, a horizontal habitat attached to a Power and Support Unit (PSU), the Chariot Crew Mobility Chassis (CMC), the Lunar Electric Rover (LER) with an attached Portable Utility Pallet (PUP), an Airlock-Derived Logistics Carrier, and a conceptual European Space Agency (ESA) Lander. Key specifications of each concept were used as the basis for the model parameters used in the analysis. These parameters for each element are listed in Table 1.

Table 1. Parameters for the element models used in the study.

\begin{tabular}{|l|c|c|c|c|}
\hline Element & Mass & Overall Length & Overall Width & Packaged Height \\
\hline Altair Lander & $8 \mathrm{t}$ & $8.8 \mathrm{~m}$ & $8.8 \mathrm{~m}$ & $6.2 \mathrm{~m}$ \\
\hline $\begin{array}{l}\text { Habitat/PSU combo } \\
\text { (w/logistics) }\end{array}$ & $12 \mathrm{t}$ & $8.1 \mathrm{~m}$ & $3.5 \mathrm{~m}$ & $4 \mathrm{~m}$ \\
\hline $\begin{array}{l}\text { LER/PUP } \\
\text { (w/logistics) }\end{array}$ & $6 \mathrm{t}$ & $5.5 \mathrm{~m}$ & $4 \mathrm{~m}$ & $3 \mathrm{~m}$ \\
\hline Chariot & $1 \mathrm{t}$ & $4.5 \mathrm{~m}$ & $4 \mathrm{~m}$ & $1.3 \mathrm{~m}$ \\
\hline Logistics carrier & $1.5 \mathrm{t}$ & $1.5 \mathrm{~m}$ & $1.5 \mathrm{~m}$ & $2 \mathrm{~m}$ \\
\hline ESA Lander & --- & --- & -- & $4.5 \mathrm{~m}$ \\
\hline
\end{tabular}

Several anticipated operational requirements, listed in Table 2, were used to set the conditions for the analyses. Some of these conditions impacted LSMS-H operations and others affected the LSMS-H design. The current concept of operations for several lunar cargo missions calls for the cargo to be offloaded from the lander before the crew arrives. As a result, the LSMS-H must be designed to perform offloading operations without direct crew interaction. Both the LSMS-H and cargo must also be configured in such a way that enables the LSMS-H to acquire different cargo elements without requiring re-rigging or other human intervention. The LSMS-H will need to be 
operated by and communicate with Earth-based controllers to facilitate offloading, even without the crew present on the lunar surface.

The LSMS-H design is further affected by the desire to land one or two units that will then be transferred between landers and other cargo handling sites. The LSMS-H must, therefore, be transportable and able to relocate itself even when the crew is not present. The design is also influenced by the need to reach all cargos to be offloaded, which may require reaching across the entire lander deck or up from a chassis or surface mount to cargos on top of the lander.

Table 2. LSMS operational requirements.

\begin{tabular}{|c|}
\hline Anticipated Operational Requirements for the LSMS \\
\hline Operable from Earth or by crew on lunar surface \\
\hline Able to engage and balance payloads without crew intervention \\
\hline Provide a manual override \\
\hline Able to relocate without crew intervention \\
\hline Able to interface with lander and chassis for mounting \\
\hline Sufficient reach to acquire all cargo \\
\hline Able to lift the heaviest payload safely \\
\hline Able to manipulate the largest payloads safely \\
\hline
\end{tabular}

\section{Offloading scenarios}

For this study, offloading scenarios were chosen that encompass the range of the LSMSH's expected primary operational modes: lander mount, chassis mount, and surface mount, some examples of which are depicted in Figure 1. The first scenario, divided into two phases, evaluated offloading a large, heavy element such as a habitat or logistics module from the Altair lander and placing the element onto an available surface mobility asset (Phase 1) and then removing the element from the mobility system and aligning and emplacing the element on the surface (Phase 2). The LSMS-H was mounted on the Altair lander for Phase 1 and on the lunar surface for Phase 2. For this scenario, the cargo was lifted at the LSMS-H elbow and the LSMS-H incorporated a rotary joint at the connection with the cargo.

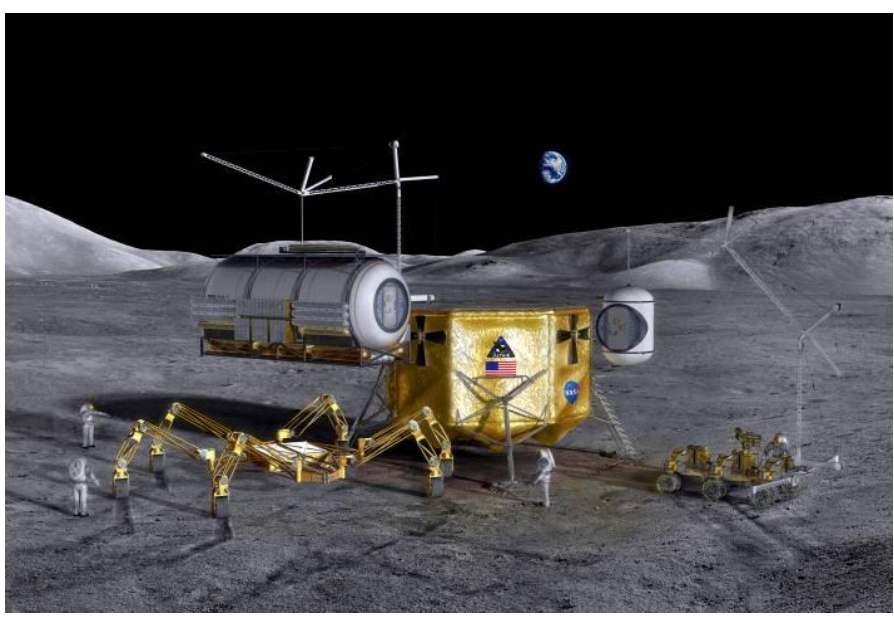

Figure 1. Lunar payload handling operations with the Heavy-lift LSMS.

The second scenario evaluated offloading a representative mid-size cargo. The Lunar Electric Rover, with attached Portable Utility Pallet, was maneuvered from the lander to the lunar surface with a lander-mounted LSMSH. For this study, the upper mass constraint for a mid-size cargo was defined as the lifting capability at the LSMS-H wrist.

The third scenario evaluated offloading a $1.5 \mathrm{t}$ cargo carrier from a third-party lander, based on the proposed ESA cargo lander, with the LSMS-H mounted to a Chariot Mobility Chassis. ${ }^{9}$ Under this scenario, a case was also run that did not include any outriggers to determine if such operations were feasible. Tip-over analysis was then used to determine outrigger size versus payload handling envelope for chassis-mounted operations.

\section{Heavy-lift LSMS Design}

The LSMS design scales easily over a wide range of reaches and payload masses. Details on the scaling laws are provided in Refs. 1 and 8 . The efficient structural design yields a total device mass for a design based on composite trusses of approximately $3 \%$ of the maximum load lifted at the wrist or $1.7 \%$ of the maximum load lifted at the elbow. The primary design drivers for the LSMS are the maximum reach, $R$, the shoulder height, $\eta R$ where $0 \leq \eta \leq$ 1 , and the maximum payload mass to be lifted at the wrist or elbow in lunar gravity (Fig. 2).

The LSMS has three primary degrees of freedom, all of which are revolute joints identified by the red dotted call-outs in Figure 2. Using the inertial frame identified in Figure 2 and starting at the ground interface (or base) of 
the device, the first revolute joint is referred to as the waist joint and it provides a simple rotation about the positive $\mathrm{z}$-axis which is represented by the angle $\theta_{l}$ measured from the positive $\mathrm{x}$-axis. The second revolute joint is located at the top of the king post at a distance $\eta R(0 \leq \eta \leq 1)$ along the positive z-axis. This joint is called the shoulder joint, and it provides a simple rotation about an axis parallel to positive y-axis that is represented by the angle $\theta_{2}$ measured from a horizontal line passing through the shoulder. The third revolute joint, called the elbow joint, is positioned at a distance $\beta R(0 \leq \beta \leq 1)$ in the positive $\mathrm{x}$ direction from the shoulder. It enables a simple rotation about an axis parallel to the positive y-axis that is represented by the angle $\theta_{3}$ measured from a line passing through the shoulder and elbow joints. The joints are actuated by electric motors which either drive hoists to actuate the shoulder and elbow or drive the waist rotation directly. Finally, the wrist is located at the end of the forearm by continuing along positive $\mathrm{x}$-axis a distance $R(1-\beta R)$.

Table 3 provides the corresponding dimensions for several designs that have been explored over the past few years in response to different payload handling requests. The first design shown in the table is the first generation test-bed tested at Moses Lake, WA in 2008. ${ }^{10}$ The design used square aluminum tubes for the primary compression members (i.e. king post, arm and forearm) and off-the-shelf components for the waist rotation, hoists, and motors. The design mass included a heavy fork-lift interface integrated into the unit to facilitate relocation in the field. Note this is the as-built weight of the field tested unit.

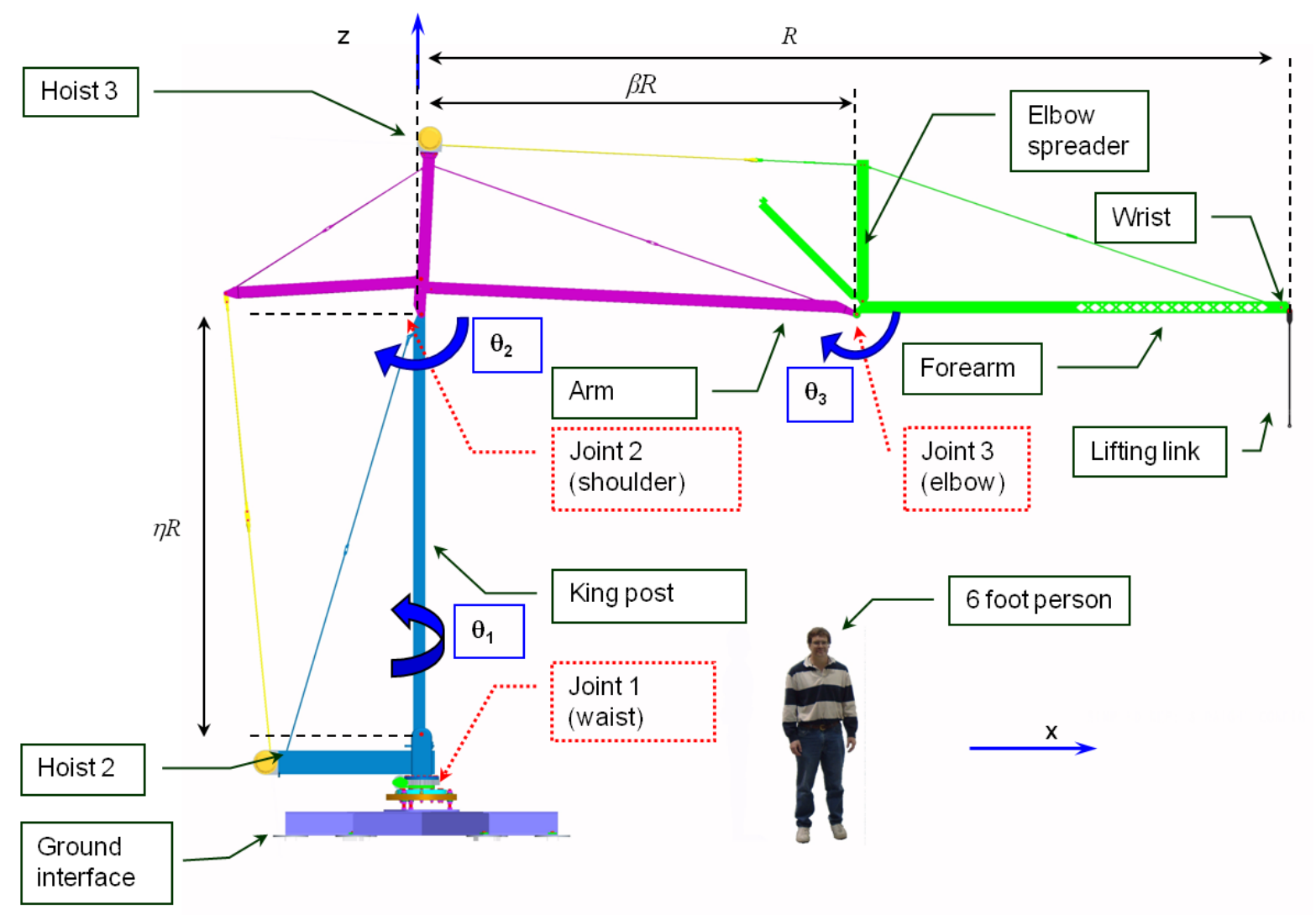

Figure 2. LSMS naming convention.

The second row in Table 3 provides details on the second generation LSMS test-bed currently being designed. This version will have three times the lifting capacity of the first generation unit and the reach increased by 1 meter, yet is projected to be $40 \%$ lighter than the first generation unit. The primary objective of the second generation test-bed is to demonstrate self offloading of the LSMS. ${ }^{11}$ Self-offloading refers to the ability of the LSMS to transfer itself from the lander deck to the surface under its own power. This is accomplished by having the wrist grasp a hard point on the lander deck, then releasing the base from the deck and transferring it to the lunar surface. The large weight savings comes from the use of more advanced structural components and the use of aluminum trusses for the compression members. 
Table 3. LSMS design dimensions and capability.

\begin{tabular}{|c|ccccccc|}
\hline $\begin{array}{c}\text { Design } \\
\text { Identifier }\end{array}$ & $\begin{array}{c}\text { Height } \\
(\eta \mathbf{R}[\mathbf{m}])\end{array}$ & $\begin{array}{c}\text { Reach } \\
(\mathbf{R}[\mathbf{m}])\end{array}$ & $\begin{array}{c}\text { Elbow Loc. } \\
(\boldsymbol{\beta} \mathbf{R}[\mathbf{m}])\end{array}$ & $\begin{array}{c}\text { Lunar Wrist } \\
\text { Capacity }([\mathbf{k g}])\end{array}$ & $\begin{array}{c}\text { Lunar Elbow } \\
\text { Capacity }([\mathbf{k g}])\end{array}$ & $\begin{array}{c}\text { Device } \\
\text { Mass[kg] }\end{array}$ & $\begin{array}{c}\text { Construction } \\
\text { Type }\end{array}$ \\
\hline Generation I & 3.75 & 7.5 & 3.76 & 1,000 & 1,742 & 309 & $\mathrm{Al}$ Tube \\
\hline Generation II & 4.25 & 8.5 & 4.26 & 3,000 & 5,226 & 190 & $\mathrm{Al}$ Truss \\
\hline Moderate Lift & 3.75 & 7.5 & 3.76 & 4879 & 8,500 & 108 & Composite \\
\hline Heavy Lift & 4.17 & 8.34 & 4.18 & 6907 & 12,033 & 169 & Composite \\
\hline
\end{tabular}

The 3rd and 4th rows of Table 3 describe reference designs developed to meet requirements obtained from lunar architecture studies. These designs take advantage of high performance composite trusses for the primary compression members, and flight-like motors are assumed with a performance of $125 \mathrm{~N}-\mathrm{m} / \mathrm{kg}$.

\section{LSMS Tip Over Discussion}

Two primary factors contribute to the reduced risk of tip over for the LSMS compared to earth-based cranes. First, there is no wind loading in the lunar environment. Second, the payloads that are to be manipulated by the LSMS are well quantified and all payloads will have been previously weighed to eliminate any uncertainties. These two factors result in a more deterministic lifting operation compared to similar earth based operations.

All operations on the lunar surface must be carefully managed to mitigate risk. Lifting payloads with the LSMS is a class of operations that necessitate proper management. It is not the purpose of this section to discuss or develop those management techniques; rather it is to demonstrate that large payloads may be offloaded from the lander deck by the LSMS without auxiliary restraint systems. In addition, when the LSMS is operating from a fixed base on the lunar surface, large payloads may be handled with simple, robust restraint systems.

\section{LSMS Tip Over Evaluated When Mounted to Altair Lander}

The first operational scenario considered is to offload a payload such as a habitat or LER from the Altair lander as illustrated in Fig. 3. The Altair lander has landed on a worst case slope of $12^{\circ}$ and the LSMS is mounted on the

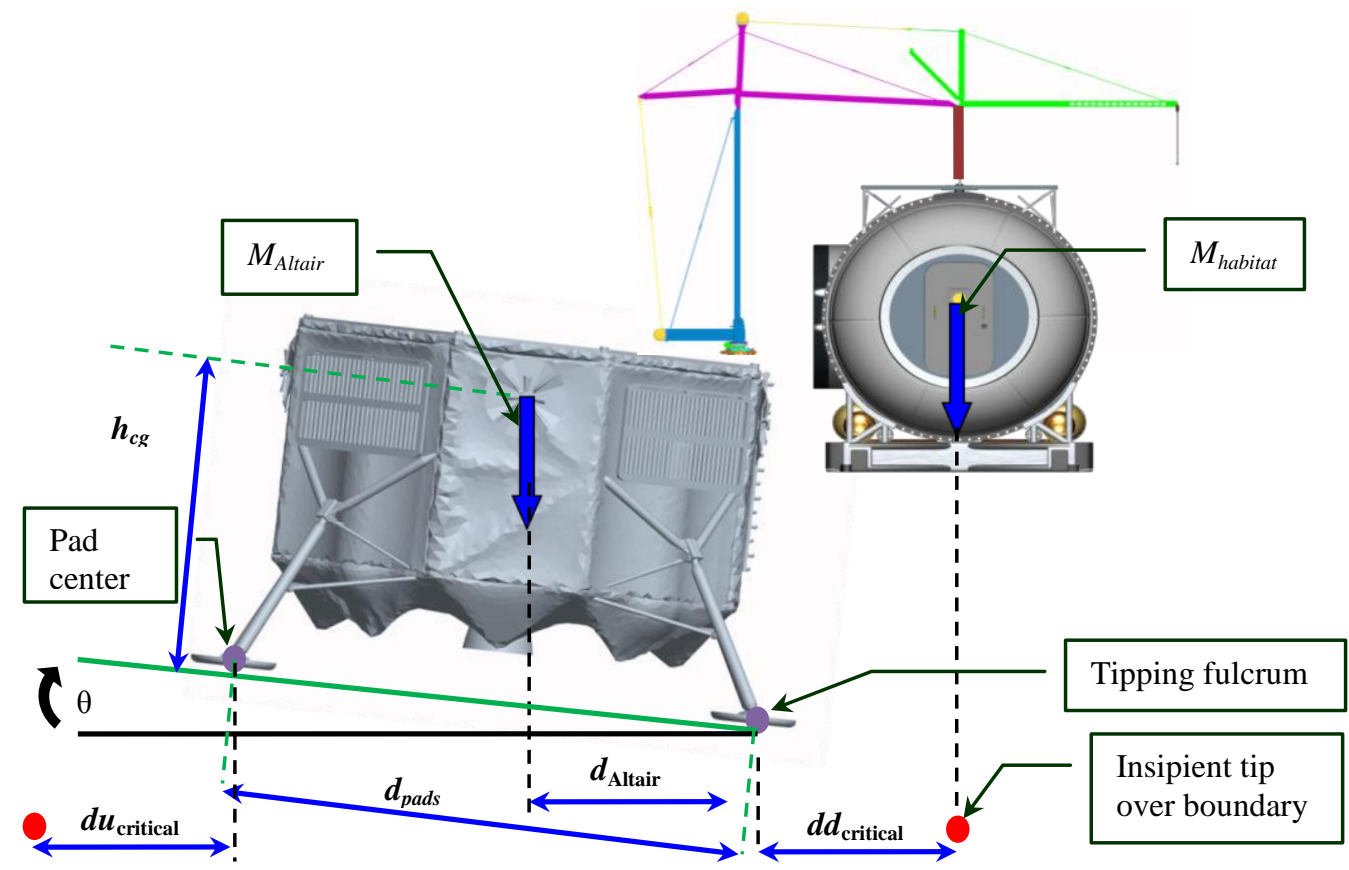

Figure 3. Notional side view of Lander on worst case slope.

down slope side. This is the worst case position for the LSMS because the slope reduces the horizontal distance from the tipping fulcrum to the CG of the lander. The tipping fulcrum is the line or point about which tip over initiates. ${ }^{12}$ Referring to Figure 3, this occurs along a line passing through the center of the lander pad perpendicular 
to the page. In a constant gravity field with no external static forces or induced dynamic forces (i.e. quasi static operation), insipient tip over occurs when

$$
\sum_{i=1}^{n} M_{i} d_{i}=\sum_{j=1}^{m} M_{j} d_{j}
$$

where there are $n$ objects on the left of the tip over boundary and $m$ objects on the right with masses $M_{i}$ and $M_{j}$ respectively and the perpendicular distances from the tipping fulcrum to the CG vector of the objects are $d_{i}$ and $d_{j}$. Neglecting the mass of the LSMS (a conservative assumption) and applying Eqn. 1 leads to

$$
M_{\text {Aitair }} d_{\text {Altair }}=M_{\text {habitat }} d d_{\text {critical }}
$$

where $d d_{\text {critical }}$ is the critical down slope horizontal distance from the tipping fulcrum to the CG of the habitat beyond which tip over occurs and $d_{\text {Altair }}$ is the horizontal distance from the tipping fulcrum to the CG of the Altair lander. From the figure, $d_{p a d s}$ is the center-to-center distance between the pads and $h_{c g}$ is the height of the CG then

$$
d_{\text {Aitair }}=\left(\frac{d_{\text {pads }}}{2}-\tan (\theta) h_{c g}\right) \cos (\theta)
$$

and thus from Eqns. 2 and 3

$$
d d_{\text {critical }}=\left(\frac{d_{\text {pads }}}{2}-\tan [\theta] h_{\text {cg }}\right) \cos [\theta] M_{\text {Aitair }} / M_{\text {habitat }}
$$

Similarly, the critical up slope distance can be calculated from

$$
d u_{\text {critical }}=\left(\frac{d_{\text {pads }}}{2}+\tan [\theta] h_{\text {cg }}\right) \cos [\theta] M_{\text {Aitair }} / M_{\text {habitat }}
$$

Thus if it is possible to lower the habitat using the LSMS-H while keeping the CG of the habitat within $d d_{\text {critical }}$ of the pad center then it is possible to offload the habitat in the worst case condition. Using the parameter values given in Table 4 leads to a limiting value of $2.62 \mathrm{~m}$ for $d d_{\text {critical }}$ of Eqns. 4. It will be shown in Section V-B that it is possible to offload the habitat from the Altair lander without violating this constraint. Note this is a conservative number because the dry mass of the lander has been used in the calculation and the mass of the LSMS, which is on the left side of the tipping fulcrum of Fig. 3, has been neglected.

The insipient tip over boundary information can be used to provide a very intuitive interface for an operator. A representation of the insipient tip over boundary can be drawn around the LSMS and its base, for example the Altair lander, as illustrated by the red box in Figure 4. This boundary will be referred to as the "tip over boundary" in subsequent discussions. The tip over boundary is a function of the load lifted by the LSMS and the location of lift, either tip or elbow. A display that shows the tip over boundary overlaid with the current location of the lifting point, identified by the round green circle, provides an intuitive display of the lifting operation. The operator needs only to keep the lifting point inside the boundary to prevent tip over. In the majority of operations, where the payload is lifted from above, the CG of the payload naturally aligns itself under the lifting point. In a side grapple operation, where the lifting point is not above the CG of the payload, a similar display can be used, accounting for the offset of the payload CG. The distance to the red boundary indicates the margin to tip over. Further, with a force sensor attached to the LSMS at the lifting interface, it is envisioned that the insipient tip over boundary would be updated dynamically as each payload was acquired. An advanced system could prevent acquisition and maneuver of payloads into situations that might lead to tip over. It is straight forward to activate additional indicators (for example visual cues or audio bells over the radio or network) based on the distance to the insipient tip over boundaries to provide warnings as the boundaries are approached. Note, in the general case of an arbitrary base support for the LSMS, the tip over boundary may not be square. This is especially true in situations where outriggers or ground anchors are used as discussed next. 


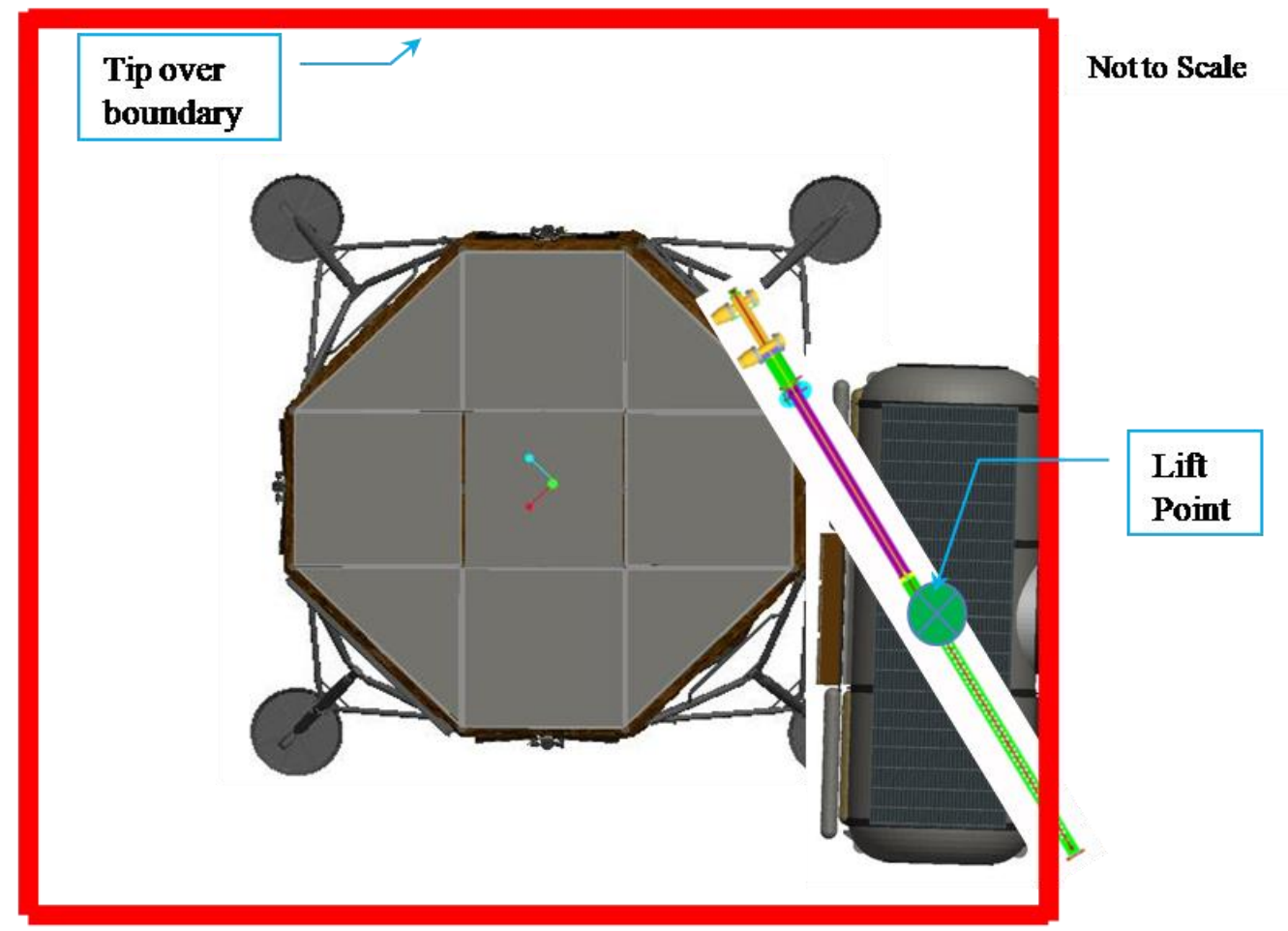

Figure 4. Notional top view with insipient tip-over boundary displayed.

\section{E. LSMS-H Tip Over Evaluated When Attached to Mobility Chassis}

The second operational scenario evaluated considers the LSMS mounted to a Mobility Chassis. In this case the Chariot chassis was assumed as illustrated in Figure 5. The LSMS is capable of transitioning from the lander deck to a mobile chassis under its own power. ${ }^{13}$ Once mounted to a mobile chassis it can be relocated as needed, operating from the mobile chassis.

The tip-over boundary dimensions depend on the stability of the mobile chassis. Many options are available to increase the stability of the mobile chassis if required, including adding mass onto the vehicle, vehicle chassis orientation, outriggers, etc. The option considered in the following discussion is a ground anchor, for example an auger. As illustrated in Figure 5, the LSMS is assumed to be attached to the end of the mobile chassis on a porch as shown. The distance, $l p_{l s m s}$ is selected to allow the LSMS to rotate 360 degrees. The CG of the mobility chassis of mass $M_{\text {chariot }}$ and length $1_{\text {chariot }}$ is assumed to be at the geometric center of the vehicle. To increase the stability of the system a ground anchor reacting a force $F_{\text {groundanchor }}$ has been placed on the end of the vehicle opposite the LSMS. In this scenario, the body of the chassis has been lowered to the ground so that the wheels no longer make contact. The LSMS is attached to a porch of length $l p_{\text {lsms }}$, the front lip of which acts as the tipping fulcrum. Generalizing Eqn. 1 to include reaction forces parallel to the gravity loads leads to

$$
\sum_{i=1}^{n} M_{i} d_{i} g_{i}+\sum_{a=1}^{b} F_{a}=\sum_{j=1}^{m} M_{j} d_{j} g_{i}+\sum_{c=1}^{d} F_{c}
$$

where $g_{l}$ is lunar gravity, represented by the Earth's gravitational constant divided by six, and $F_{a}$, $F_{c}$ represent reaction forces on the left or right of the tipping fulcrum respectively where the positive direction has been taken to correspond to the gravity load. Neglecting the mass of the LSMS again, and applying Eqn. 6 to the situation illustrated in Figure 5 leads to

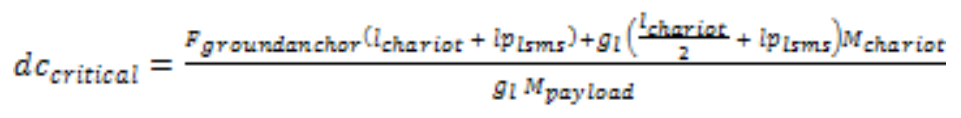


where $d c_{\text {critical }}$ is the critical horizontal distance from the tipping fulcrum to the insipient tip over limit when maneuvering a payload with mass $M_{\text {payload }}$ as illustrated in Figure 5.

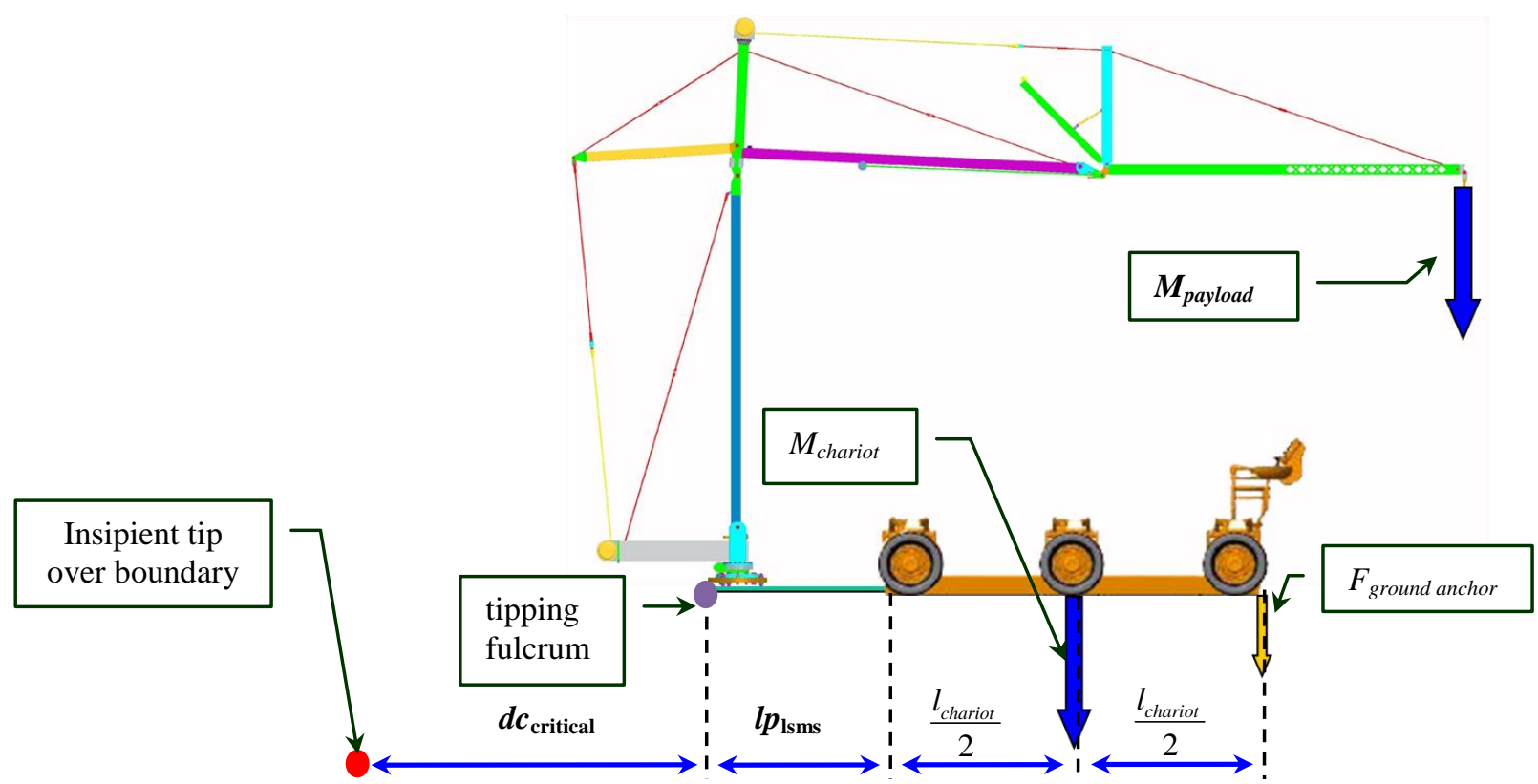

Figure 5. Tip-over limits when mounted on Mobility Chassis with and without outriggers.

Equation 7 allows several options to be evaluated rapidly. Using the parameter values given in Table 3, where $M_{\text {payload }}$ has been selected to be larger than $M_{\text {chariot }}$ to highlight the ability to handle large payloads with moderate reaction loads, leads to a limiting value of $2.62 \mathrm{~m}$ for $d c_{\text {critical }}$ when there is no ground anchor present, i.e. $F_{\text {groundanchor }}=0$. A value of $2620 \mathrm{~N}$ (in earth gravity) for $F_{\text {groundanchor }}$ allows the $1500 \mathrm{~kg}$ payload to be manipulated anywhere within the $8.34 \mathrm{~m}$ reach of the LSMS, which is the full reach of an LSMS sized to off-load the Altair lander, as indicated in Table 4.

\section{F. LSMS Tip Over Evaluated When Located on Surface and Maneuvering Habitat}

A third operational scenario considered is to position the habitat at the outpost site as illustrated in Fig. 6. The LSMS is capable of transition from the lander deck to a mobile chassis under its own power. ${ }^{14}$ Once mounted to a mobile chassis it can be relocated as needed and then can transition to a fixed base or operate from the mobile chassis. In this evaluation, the LSMS-H is assumed to be a free standing unit. The operational scenario has the habitat arriving on a pair of chariot mobile chassis or on an ATHLETE. The LSMS-H is used to lift the habitat from the vehicle(s) and then position the habitat next to an existing unit. In this maneuver the LSMS-H may need to rotate up to five degrees. To accommodate aligning the habitat during this maneuver a rotational degree of freedom is envisioned at the lifting link.

The following discussion describes one of many possible ways to accomplish this task. The operational assumption is that this is an infrequent task that would benefit from a custom solution to reduce both overall system complexity and required launch-mass. The approach described is to add a pair of light-weight guy wires to counteract the overturning moment as the LSMS-H lifts the habitat, illustrated by the green lines in Fig. 6. It will be shown that for reasonable guy locations, the resulting loads in the guy wires are small, on the order of what a 5/16 inch grade 8 bolt and 5/16 inch cable can withstand (with a Factor of Safety of 3 to ultimate load).

Summing moments about the tipping fulcrum identified in Fig. 6 leads to

$$
F_{g u y}=\frac{M_{\text {habitat }} g_{1} R}{\left(\eta n R+\hbar_{g m}\right) 4 \cos (\beta) \cos (\alpha)}
$$

where $F_{g u y}$ is the force in the guy wire, $\alpha$ is the slew $1 / 2$ angle, $\beta$ is the guy angle relative to the horizontal, $h_{g m}$ is the height of the ground mount the LSMS-H is attached to, $R$ is the reach of the LSMS-H, and $\eta$ is the ratio of the 
shoulder height to reach for the LSMS-H as shown in Fig. 6. Using the parameters given in Table 4 leads to a guy force, $F_{g u y}$, of $12,429.2 \mathrm{~N}$. The breaking strength of a 5/16 inch fine thread grade 8 bolt is $38,700 \mathrm{~N}$ and a $5 / 16$ inch cable is $40,000 \mathrm{~N}$ providing a factor of safety of 3 to ultimate strength. This is a modest load that can be managed a number of ways including ground anchors, additional guy wires or longer guys approaching the surface at a shallower angle.

$\alpha$

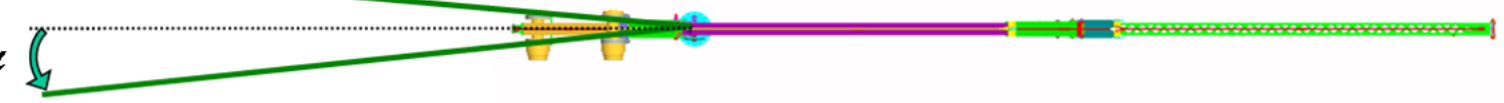

a) Top view of tension guy support, showing slew half-angle.

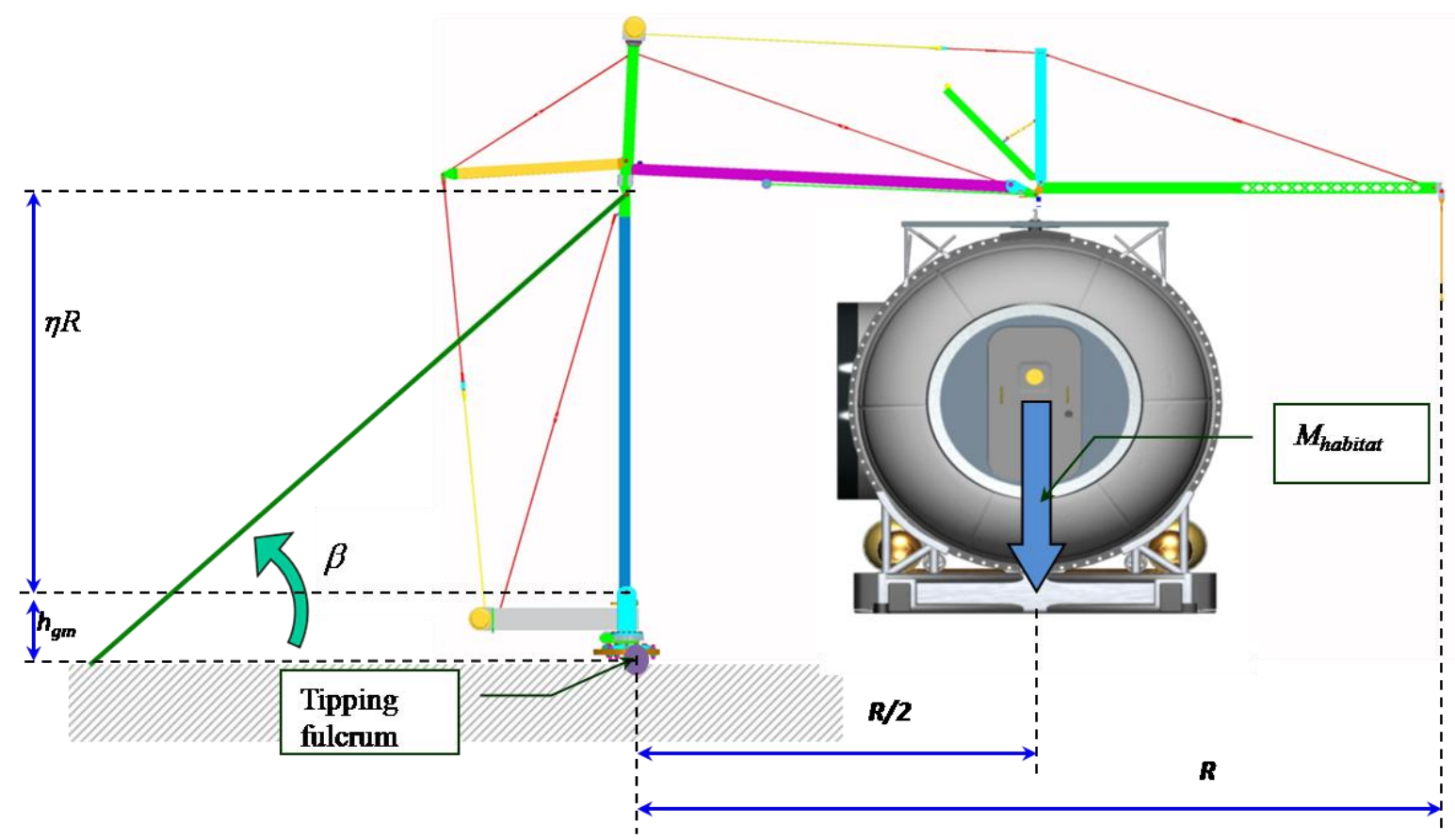

b) Side view of tension guy support.

Figure 6. Tension guy support to augment LSMS-H during surface-mounted heavy lift operations.

Table 4. Masses and dimensions used in numeric examples.

\begin{tabular}{|c|ccl||cccl|}
\hline $\begin{array}{c}\text { Design } \\
\text { Identifier }\end{array}$ & $\begin{array}{c}\text { Value in } \\
\text { Example }\end{array}$ & Units & $\begin{array}{c}\text { Design } \\
\text { Identifier }\end{array}$ & $\begin{array}{c}\text { Value in } \\
\text { Example }\end{array}$ & Units & \\
\hline$M_{\text {Altair }}$ & 8533 & $\mathrm{~kg}$ & dry mass & $\mathrm{g}_{1}$ & $9.81 / 6$ & $\mathrm{~m} / \mathrm{s}^{2}$ & lunar gravity \\
\hline$M_{\text {habitat }}$ & 12033 & $\mathrm{~kg}$ & habitat mass & $\theta$ & 12 & $\mathrm{deg}$ & $\begin{array}{l}\text { worst case lunar surface } \\
\text { slope }\end{array}$ \\
\hline$M_{\text {payload }}$ & 1500 & $\mathrm{~kg}$ & payload mass & $\beta$ & 45 & $\mathrm{deg}$ & guy angle to horizontal \\
\hline$M_{\text {chariot }}$ & 1065 & $\mathrm{~kg}$ & bare vehicle & $\alpha$ & 3 & $\mathrm{deg}$ & required slew $1 / 2$ angle \\
\hline$R$ & 8.34 & $\mathrm{~m}$ & LSMS reach & $\eta$ & 0.5 & $\mathrm{~m}$ & shoulder height ratio \\
\hline$d_{\text {pads }}$ & 9.546 & $\mathrm{~m}$ & $\begin{array}{l}\text { center to center } \\
\text { of Altair pads }\end{array}$ & $h_{c g}$ & 4.238 & $\mathrm{~m}$ & height to Altair c.g. \\
\hline$l_{\text {chariot }}$ & 4 & $\mathrm{~m}$ & chariot length & $h_{g m}$ & 0.5 & $\mathrm{~m}$ & ground mount height \\
\hline$l_{p_{\text {lsms }}}$ & 1.5 & $\mathrm{~m}$ & porch length & & & & \\
\hline
\end{tabular}




\section{Synergistic Engineering Environment Simulations}

The Synergistic Engineering Environment (SEE) is a simulation, analysis, and visualization system designed to couple engineering data with graphical models within a virtual environment to give engineers and scientists the ability to study the operations and planning of spacecraft and spacecraft systems. The SEE provides the user a time based virtual environment, allowing the user to navigate through time and space to investigate the mission at hand. By combining the data from multiple design teams and disciplines, the SEE can provide insight into the entire system and allow for better understanding of the impacts that one aspect of a mission or design has on another. A sample screen shot of the SEE can be seen in Figure 7.

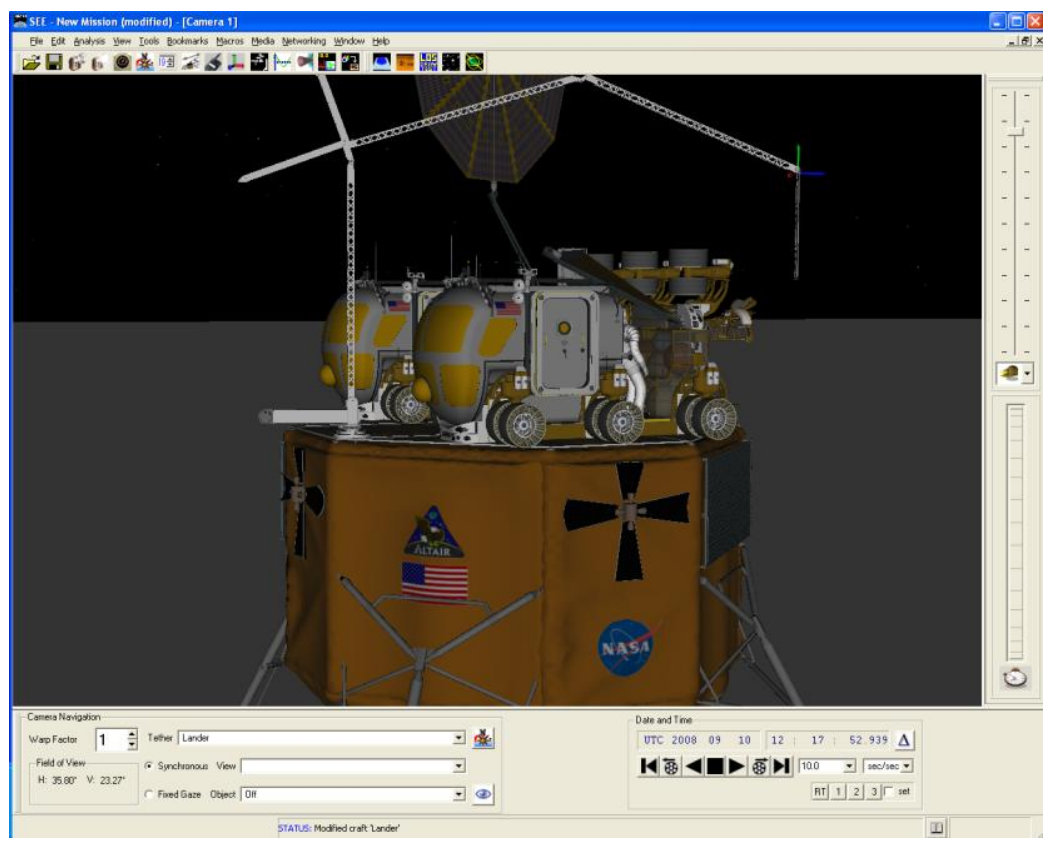

Figure 7. Sample Screen Shot of the LSMS-H Analyses in SEE.

The SEE was initially developed using the International Space Station as the proof of concept for analyzing complex spacecraft operations. It was later expanded to allow for the analysis of any number of spacecraft anywhere in the solar system. The SEE is utilized by the ISS Mission Operations Directorate and has been used to support numerous programs and projects at NASA including the Mars Exploration Rover program, Hyper-X, Ares and Ares 1-X, Lunar Architecture studies and future spacecraft concepts.

\section{A. Analyses}

To support the LSMS-H study, SEE was utilized to conduct several analyses. The first objective was to determine whether the LSMS-H, as designed, could successfully unload the necessary payloads. This included the reach and location of the LSMS-H combined with the position and design of the payloads. Second was the ability of the LSMS-H to perform these operations while maintaining the CG within acceptable limits developed during the preliminary tip-over analyses previously discussed. This included Lander-mounted, Chariot-mounted, and surfacemounted LSMS-H operations.

The first study conducted with the SEE was a basic analysis of the LSMS-H capabilities for unloading the payloads based on LSMS-H reach and joint rotation capabilities (payload mass not considered). To enable this study, the Altair-based Lander, a prototype ESA Cargo Lander, the habitat, the Chariot, and the LSMS-H were brought into the SEE. These can be seen in Figure 8 through Figure 10. Each of the primary joints of the LSMS-H was modeled within the SEE. For each payload configuration, the location of the LSMS-H was varied to allow for the best reach onto both the lander deck and lunar surface. Each payload unloading operation was simulated using a series of joint operations coupled with grapple and release operations. 


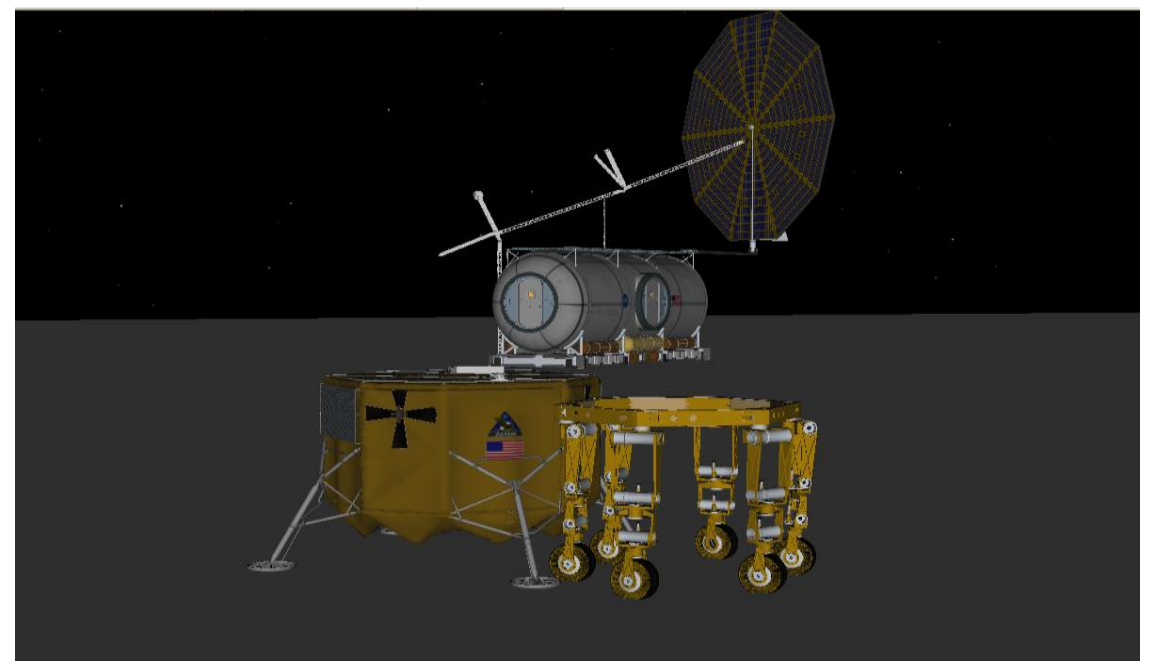

Figure 8. LSMS-H, Lander, Habitat, and Athlete in SEE.

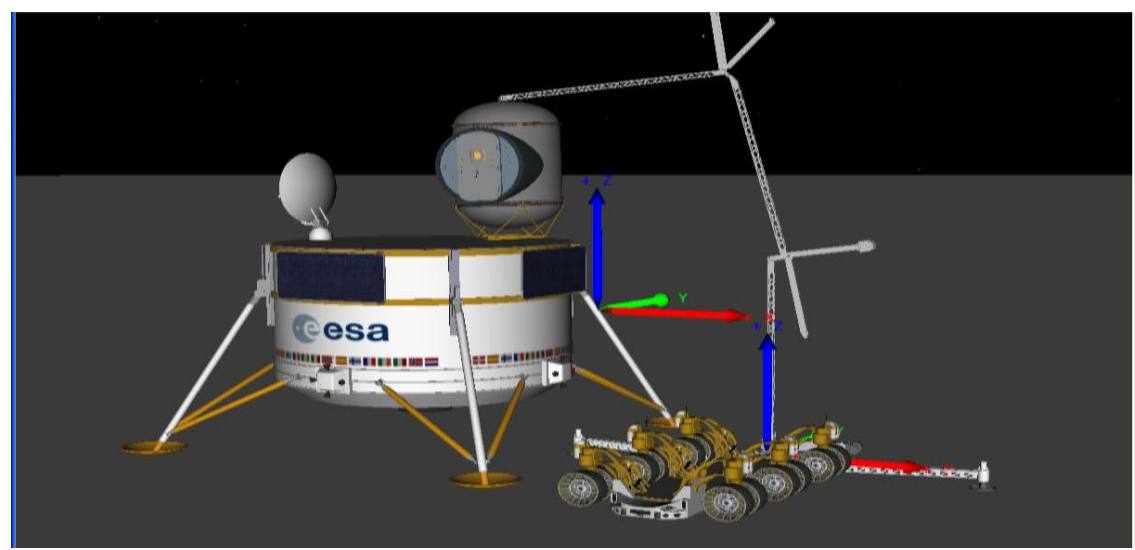

Figure 9. Chariot, LSMS-H, and ESA Lander in SEE.

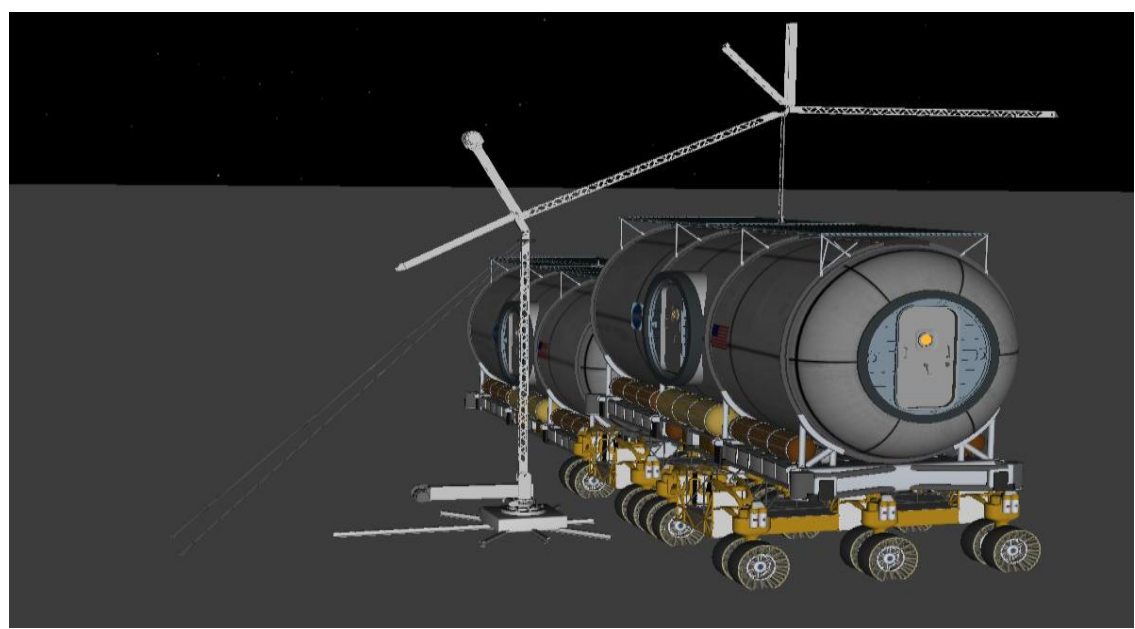

Figure 10. LSMS-H, Chariots and Habitats in SEE.

A more detailed study was conducted to investigate the CG location during the offloading operations. Based on values obtained from the Lunar Surface Systems team, mass properties for the Altair lander, the LSMS-H, the habitat, and the Chariot were entered into the SEE. The operation of the LSMS-H was refined to maintain the CG of 
the system within a predefined zone during all motions of the LSMS-H and payload. Two different techniques were used to verify these operations. The first was a visual inspection of the system's CG, shown using an icon within the scene, with respect to a tip-over boundary limit, shown as a bounding "box" within the scene. Second, the CG value was displayed on-screen and was checked against the bounding "box" values. These techniques can be seen in Figure 11 and Figure 12.

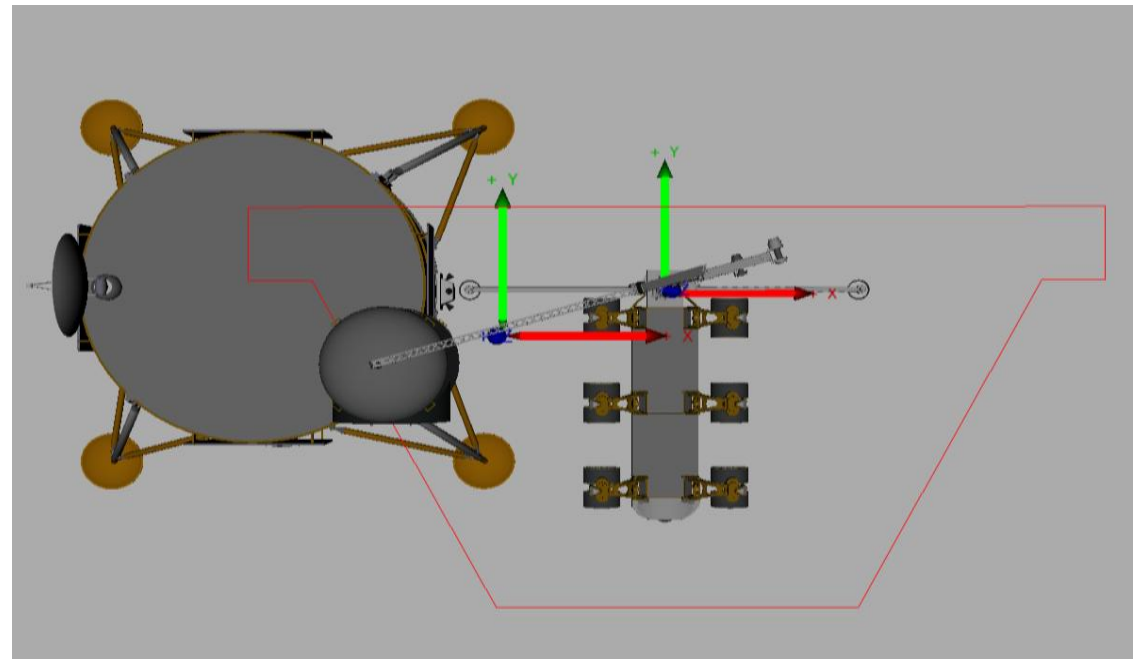

Figure 11. CG reference frame icon and bounding "Box" (red outline) in SEE.

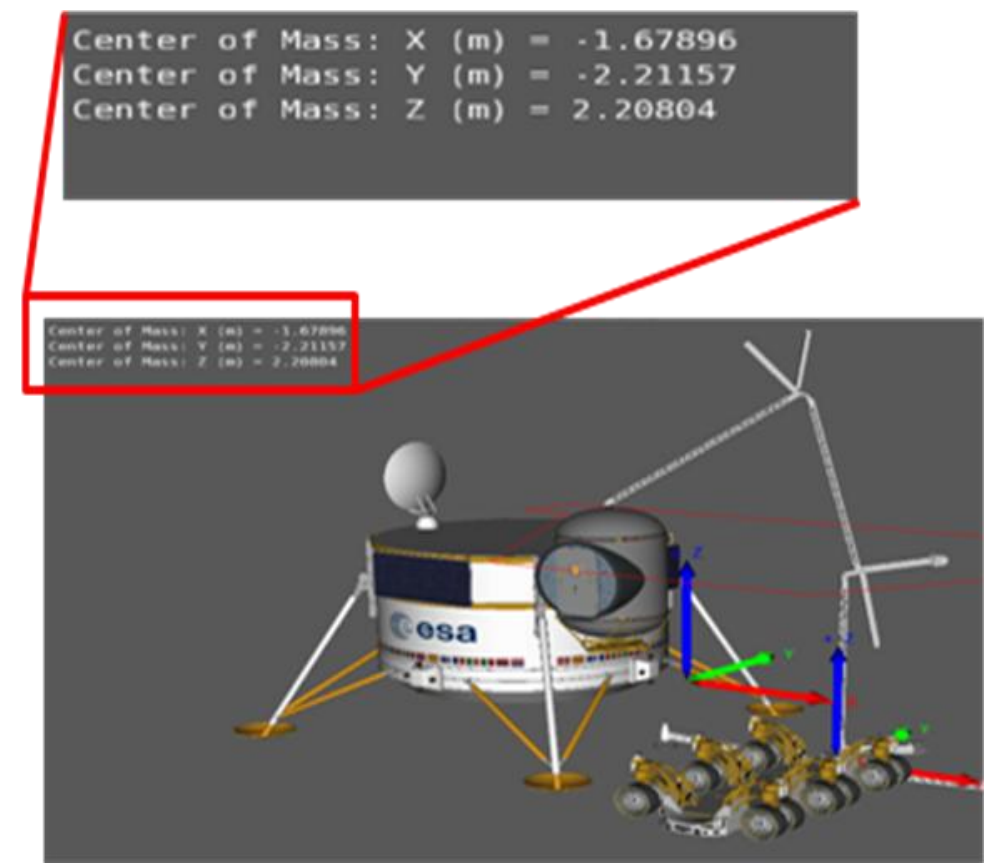

Figure 12. Numeric CG coordinate display in SEE.

\section{B. Analysis Results}

The analyses of the LSMS-H operations from Lander, Chariot and ground mounting locations showed that the LSMS-H could perform the required offloading operations safely, but at times with the payload approaching the tipover boundary. However, several "enhancements" were noted that, if incorporated, would improve the safety margin of the operational envelope. Furthermore, the analyses demonstrated the importance of packaging and location. The 
location of the LSMS-H and the planned offloading operations would need to be considered early on when planning payloads layouts for the lander deck.

Operational limits for the lander-mounted LSMS-H are driven primarily by its position on the lander. There were two possible attachment locations for the LSMS-H in the habitat unloading scenario: at the edge of the deck on a side where a leg is attached to the Lander, or at the edge on a side without a leg. Placing the LSMS-H on a 'non-leg side' forced the payload towards the wrist of the LSMS-H arm during offloading operations, creating a tip over hazard. Placing the LSMS-H on a 'leg side' allowed the payload to be kept closer to the elbow joint, reducing the moment created by the payload's mass. The single habitat offload scenario allowed plenty of deck space for the LSMS-H to self deploy without creating any collision issues. The LSMS-H was able to successfully unload the habitat to an Athlete positioned adjacent to the Lander without the use of additional features such as a swivel joint on the lifting link or a variable length lifting link. However, to unload the habitat to the surface or to a Chariot would require a variable-length lifting link.

The placement of the LSMS-H in the LER offloading scenario was the same as that utilized in the habitat offloading scenario. In this scenario, however, the initial movements of the LSMS-H were limited due to having two LERs and one CMC on the Lander deck, as seen in Figure 7. Large rotations of the kingpost, while the cable support at the base of the LSMS-H was deployed, were restricted to prevent collisions of the support with the LERs. Consequently, the kingpost should be positioned so that the base cable support extends away from the center of the lander, rather than towards it. This allows the kingpost to be rotated to a position where the LSMS-H arm can reach the CMC without creating a collision between the base cable support and an LER. Additionally, the deployed LER solar array can create a collision hazard depending on its configuration. The solar array can be moved to allow clear access to the CMC but it may be at a non-optimal incidence angle. Once the CMC is grappled, it can be lifted from the Lander deck and placed on the surface in two different locations. Placing the CMC on the same side of the Lander as the LSMS-H requires a kingpost rotation of greater than 180 degrees but allows the LSMS-H to place the $\mathrm{CMC}$ on the surface without the use of a variable-length lifting link. Alternately, the CMC can be placed on the side of the lander next to the LER with the stowed solar array, requiring a kingpost rotation of $\sim 90$ degrees. However, the LER restricts the motion of the LSMS-H shoulder joint and the CMC can only be placed on the surface with the use of a variable-length lifting link. Once the CMC has been offloaded, the LERs can be offloaded without issue.

Placing the LSMS-H onto the Chariot through an attachment mechanism at the rear of the vehicle provides a mobile solution for payload operations. There were no issues associated with stowing or redeploying the LSMS-H while attached to the Chariot. During offloading operations, rotations of the kingpost were limited to about 90 degrees in either direction from the longitudinal axis of the chariot. Rotations larger than 90 degrees caused the support strut at the base of the kingpost to collide with the wheels of the Chariot. The Chariot-mounted LSMS-H was used to offload a cargo container from the representative ESA lander. The use of a variable length lifting link or swivel joint was not required to transfer the payload from the ESA lander deck to the chariot. However, a set of outriggers, as shown in Figure 13, was required to expand the operational envelope and prevent tip over of the Chariot/LSMS-H during offloading operations. Additionally, the Chariot had to be parked in close proximity to the Lander, such that the outriggers extended within the base of the Lander's legs. With the outriggers extended and the Chariot parked close to the Lander, the LSMS-H was able to offload a 1,500 kg payload, but with only small margins on the tip over box. Margins could be increased if desired by increasing the length of the outriggers.

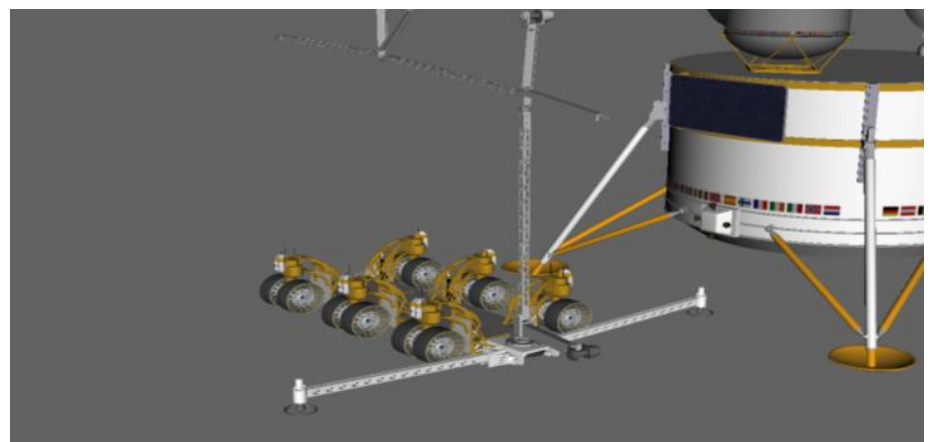

Figure 13. Outrigger concept for Chariot-based LSMS-H in SEE.

To lift and maneuver heavy payloads with the LSMS-H mounted directly to the lunar surface, a ground anchoring system is required. This system reacts the overturning moments that were previously reacted by the lander 
or Chariot. Guy wires attached to ground anchors were connected to the kingpost just below the shoulder joint and extended behind the LSMS-H to form a 45 degree angle with the ground. The two cables were placed with an angle of 10 degrees between them, limiting the rotation of the kingpost. A rotation of the kingpost greater than \pm 5 degrees from the center line of the guy wires would create a collision between the tension members of the LSMS-H and the guy wires. The guy wires were modeled in the SEE by adding point masses at the anchor locations sized to represent the tension in the anchor lines. It should also be noted that the lifting link is kept at the elbow rather than at the tip due to the large load of the habitat. Extending the lifting link further along the boom would create a tip over hazard.

\section{Correlation between Lunar and Terrestrial Ground Support Equipment}

Handling multi-ton flight systems on another planetary body at $1 / 6$ gravity in the vacuum of space can pose significant challenges and problems, especially if done remotely from some 250,000 miles away. When examining methods to remotely acquire and release cargo elements with the LSMS-H, both the expected Earth-based and lunar handling requirements were considered. Although the equipment required for $1 \mathrm{~g}$ operations will, by necessity, be different than the LSMS-H, several advantages can be gained by synchronizing the design and procedures so that the LSMS-H and ground handling systems can acquire the cargo in the same manner to the greatest extent possible.

Using common payload interfaces and identical acquisition mechanisms for both lunar and terrestrial handling operations simplifies the design, saves weight and cost, and minimizes differences so that lunar operations mimic terrestrial operations as closely as possible. Utilizing common hardware also allows for verification of the lunar rated hardware and operations on Earth before launch, both through developmental and training analogs, or "dry runs", and when the flight elements are assembled, integrated, and tested on Earth in preparation for launch. Incorporating the same lunar surface and ground handling system elements into the design, in particular, common payload interfaces and identical acquisition mechanisms, will allow realistic dry runs to be performed. Any problems discovered with the interfaces and mechanisms on Earth can be addressed prior to launch, reducing the potential for issues on the lunar surface.

Including the Mission Operations personnel and Flight Crew in the dry runs as much as possible (when applicable) is important for them to get first-hand knowledge and experience with the hardware before performing the same tasks on the lunar surface. These rehearsals will help create and then verify flight procedures before they are performed on the Moon, and can also be used to understand the implications of the lunar time delay. The experience gained by handling flight hardware on Earth using Ground Support Equipment (GSE) can be applied to very similar operations needed on the Lunar surface and many of those lessons learned will be incorporated into the design of the Lunar Elements and the Lunar/Earth GSE.

One challenge with handling flight hardware on Earth is configuring the flight hardware and GSE before performing the handling operation, as this requires a great deal of time and resources. Another problem is proper alignment between the flight element and its handling GSE. Misalignment can cause the flight hardware to jam or impact adjacent hardware during removal/installation operations. By utilizing common Earth and lunar handling procedures and equipment, lunar cargo elements and handling equipment can be pre-rigged and tested on Earth to assure proper configuration and alignment. Then, once on the lunar surface, offloading operations will be the reverse of Earth-based loading operations, which will reduce the time required for lunar payload handling operations, simplify the work needed to prepare the cargo and handling equipment, simplify lunar operations, avoid problems of trying to align handling systems and lunar elements, and help assure the lunar operations will work because they were performed on Earth first.

\section{Conclusion}

Through this study, we have found that the LSMS-H is capable of performing heavy-lift cargo handling operations with only minor modifications to expand lifting capability and reach. The LSMS-H is able to perform these cargo handling operations safely, while maintaining the system CG within acceptable bounds. It was determined that for chassis-mounted operations, a ground anchor or outriggers are required to ensure a sufficient CG envelope for safe operations. Although a successful configuration for each offloading scenario was found, enhancements to the LSMS-H system, such as a variable length lifting link or a swivel joint, were identified that increase the system's versatility and operational capability. A variable-length lifting link increases the options for lowering cargo from the lander to the surface or onto surface vehicles and can improve clearances. A swivel joint can rotate the payload, providing greater accuracy for positioning and alignment and also improving clearances. The LSMS-H has shown itself to be a capable asset for lunar surface operations, not only as a lunar surface handling system, but also as a valuable and versatile addition to any architecture. 


\section{References}

${ }^{1}$ Doggett, William, Dorsey, John, Collins, Tim, King, Bruce and Mikulas, Martin, "A Versatile Lifting Device for Lunar Surface Payload handling, Inspection \& Regolith Transport Operations," STAIF-2008, Feb. 10-14 2008.

${ }^{2}$ Heverly, Matthew and Matthews, Jaret, "A Wheel-on-Limb Rover for Lunar Operation," Proceedings of the 9th International Symposium on Artificial Intelligence, Robotics and Automation in Space (iSAIRAS), February 25-29, 2008.

3 "Synergistic Engineering Environment Build II Users Guide", Technical Report No 07-16, Analytical Mechanics Associates, Inc, Hampton, VA, November 2007

${ }^{4}$ Adinolfi, P. J., and, Heinz, F. A. Jr., "Design Study of Special Purpose Systems for the Lunar Surface," NASA CR-61077, April 30, 1965.

5 Eagle Engineering, "Lunar Surface Construction and Assembly Equipment Study: Lunar Base Systems Study Task 5.3," NASA CR-172105, September, 1988.

${ }^{6}$ NASA, "NASA's Exploration Systems Architecture Study, Final Report," NASA TM-2005-214062, 2005.

${ }^{7}$ Shapiro, H. I., et al., Cranes and Derricks, McGraw-Hill Inc., 1980, $2^{\text {nd }}$ ed. 1991.

${ }^{8}$ Dorsey, John T., Mikulas, Martin M., and Doggett, William R., "Preliminary Structural Design Considerations and Mass Efficiencies for Lunar Surface Manipulator Concepts," AIAA Space 2008 Conference and Exposition September 9-11, 2008, San Diego, California, AIAA-2008-7916.

${ }^{9}$ NASA, "Small Pressurized Rover Concept", NF-2008-10-464-HQ, 2008.

${ }^{10}$ Doggett, William R., King, Bruce D., Jones, Thomas C., Dorsey, John T., and Mikulas, Martin M., "Design and Field Test of a Mass Efficient Crane for Lunar Payload Handling and Inspection - The Lunar Surface Manipulation System." AIAA Space 2008 Conference and Exposition, 9 - 11 September 2008, San Diego, California, AIAA 2008-7635.

${ }^{11}$ Dorsey, John T., et al., "Developments to Increase the Performance, Operational Versatility and Automation of a Lunar Surface Manipulation System,” AIAA Space 2009 September 14-17, 2009, Pasadena, California, AIAA 2009-6795

${ }^{12}$ Shapiro.

${ }^{13}$ Dorsey, et al., 2009.

${ }^{14}$ Dorsey, et al., 2009. 